\title{
Alguns apontamentos sobre o texto de apresentação da Gramática Contemporânea da Língua Portuguesa
}

\author{
Portuguese language: contemporary \\ grammar in texts
}

Juciane Ferigolo Parcianello*

Resumo: Buscamos, neste trabalho, estabelecer um diálogo entre as leituras realizadas durante o segundo semestre letivo de 2009, na disciplina A constituição do ensino de língua no Brasil, e o exercício analítico do texto de apresentação da Gramática Contemporânea da Língua Portuguesa (1994), de José de Nicola e Ulisses Infante, a fim de observarmos se a proposta de trabalho apresentada pelos autores da referida gramática condiz com o modo como são abordados, discutidos e problematizados os conteúdos gramaticais. Como finalidade última, visamos entender que concepções de língua, gramática, ensino de língua, aluno e professor estão sendo veiculadas pela referida gramática. Palavras-chave: Gramática. Ensino de língua. Contradição.

Abstract: This article intends to establish a dialogue between the readings done on the second semester of 2009 for the course The teaching of language in Brazil (A constituição do ensino de língua no Brasil), and the analysis of the introduction of the Gramática Contemporânea da Língua Portuguesa (1994), by José de Nicola and Ulisses Infante. The aim of this analysis is to see if the authors' proposal matches the way the grammatical contents are approach, discussed and problematized. A broader goal is to understand what conceptions of language, grammar, language teaching, student and teacher are conveyed in this reference grammar.

Keywords: Grammar. Language teaching. Contradiction.

\section{Introdução}

O ensino de língua portuguesa, desde há muitas décadas, vem sendo alvo de incansáveis discussões, pois já é lugar-comum afirmar seu caráter problemático e ineficiente diante da função que deveria desempenhar e não

\footnotetext{
${ }^{1}$ Trabalho final da disciplina A constituição do ensino de língua no Brasil, ministrada pela professora Graziela Lucci de Ângelo.

*Aluna do Doutorado em Letras e bolsista da CAPES, na área dos Estudos Linguísticos, da Universidade Federal de Santa Maria (UFSM), sob orientação da Professora Doutora Eliana Rosa Sturza. E-mail: jferigolo@yahoo.com.br
} 
desempenha: proporcionar aos alunos do Ensino Fundamental e Médio uma formação tal, que lhes possibilite concluir doze anos de estudo com a capacidade de ler e interpretar o mundo, bem como de agir criticamente diante das mais diversas situações que a vida lhes apresenta. Não é este, no entanto, o resultado da permanência de mais de uma década em sala de aula por parte dos estudantes que aprendem, de modos e em níveis diferenciados, os mesmos conteúdos. Infelizmente, a maioria deles conclui o Ensino Médio com muita dificuldade no momento de expor suas ideias e de produzir um enunciado coerente e coeso. Chegamos, então, ao ponto central da discussão que propomos nesse artigo e que pode ser resumido pela seguinte pergunta: por que, apesar de tantos anos de estudo da "língua portuguesa" - sabemos que o estudo é da gramática da língua portuguesa - os estudantes de nossas escolas não conseguem usá-la adequadamente em situações que exigem certa formalidade e certo domínio da norma culta?

No decorrer deste trabalho tentaremos responder a tal pergunta, não de maneira direta, objetiva, já propondo soluções, mas pela análise do texto de apresentação da 12 a edição da Gramática Contemporânea da Língua Portuguesa (1994), de José de Nicola e Ulisses Infante, e pela problematização de alguns aspectos que compõem o conteúdo dessa obra. Tal exercício analítico nos permitirá constatar se há realmente incoerência(s) entre a proposta inicial dos autores, presente no texto de apresentação, e o modo como os conteúdos gramaticais são elencados e desenvolvidos. Salientamos que o ensino de regras gramaticais como sinônimo de ensino de língua portuguesa é apenas um dos elementos problemáticos de nosso ensino. A ele se somam fatores sociais, econômicos, históricos e pedagógicos ou, nas palavras de Magda Soares (2002), "condições internas e externas". Neste artigo vamos nos deter nas condições internas - conteúdos priorizados e ensinados e a metodologia de ensino -, embora de alguma forma tenhamos que tocar nas condições externas - contexto sócio-histórico de produção da referida gramática -, para que possamos entender a posição de Nicola e Infante como resultante de tais condições. A escolha deste objeto de análise não foi aleatória. Ocorreu em virtude de ter sido o material base das aulas de língua portuguesa durante os três anos de Ensino Médio que cursamos. Realizar um estudo, mesmo que breve, de alguns aspectos deste suporte didático é para nós uma forma de problematizar o ensino de língua materna a partir de condições sócio-históricas definidas.

Outra questão que nos interessa desenvolver neste trabalho é aquela que se refere aos conceitos de língua, gramática, ensino de língua, aluno e 
Alguns apontamentos sobre o texto de apresentação da Gramática Contemporânea ...

professor veiculados pela Gramática Contemporânea da Língua Portuguesa (1994). Observar com atenção tais pontos nos ajudará a responder, mesmo que parcialmente, à pergunta inicial que lançamos.

\section{1. $O$ cenário educacional e o ensino de língua na segunda metade do século XX - o período ditatorial e pós-ditatorial}

A década de 1950 é um importante marco de mudanças no cenário educacional brasileiro em virtude da chamada "democratização" da escola (SOARES, 2001). O ensino, que até então era acessível apenas aos filhos de famílias abastadas, passa a ser direito de todos aqueles que vivem em território brasileiro. Houve, portanto, um aumento bastante significativo do público discente nas escolas, fato este que exigiu reformas urgentes nas diretrizes e bases da educação pública. No que tange ao ensino de língua portuguesa, não houve outro modo se não modificar o elenco de conteúdos a serem ensinados e a didática de ensino, já que "as condições escolares e pedagógicas, as necessidades e exigências culturais passam, assim, a ser outras bem diferentes" (SOARES, 2002, p.167). Reduz-se o trabalho de leitura dos clássicos da literatura e a produção textual e prioriza-se o estudo da gramática, alternado à leitura de textos diversificados.

Segundo Magda Soares, os anos 1970 e as primeiras décadas dos anos 1980 "constituem um hiato nessa primazia da gramática no ensino do português”, com o surgimento da nova Lei de Diretrizes e Bases da Educação (Lei n ${ }^{0}$ 5692/71), alicerçada nos modelos educacionais do regime militar.

A nova lei que, sob a égide desse governo, reformulou o ensino primário e médio, punha a educação, segundo os objetivos e a ideologia do regime militar, a serviço do desenvolvimento. A própria denominação da disciplina foi alterada: não mais português, mas comunicação $e$ expressão, nas séries iniciais do então criado $1^{\circ}$ grau, e comunicação em língua portuguesa, nas séries finais desse grau; só no $2^{\circ}$ grau o foco em "comunicação" desaparece da denominação que, nesse grau, passa a ser Lingua portuguesa e literatura brasileira. Coincidindo com essa mudança de caráter político e ideológico, e reforçando-a, surge nos anos 1970, como quadro referencial para a análise da língua, transposta da área dos meios eletrônicos de comunicação, a teoria da comunicação. A concepção da língua como sistema prevalece até então no ensino da 
gramática, e a concepção de língua como expressão estética, prevalente inicialmente no ensino da retórica e da poética e, posteriormente, no estudo de textos, são substituídas pela concepção da língua como comunicação (2002, p. 169).

A educação, neste período, ganhou nova roupagem: o aluno, que outrora era preparado para entender os fatos do mundo a sua volta, opinando e refletindo a respeito deles, agora deveria receber uma formação que lhe permitisse ocupar um lugar no mercado de trabalho. Ou seja, o ensino ganha um matiz mais pragmático. Carlos Alberto Faraco (2008), ao encontro do que pontua Magda Soares, caracteriza o ensino dos anos 1970 como "pedagogia tecnicista". No que compete ao ensino de língua portuguesa, conforme o referido autor, a consequência imediata dessa reforma educacional foi a prática de uma "psdeudomodernização dos temas e dos procedimentos de ensino com ênfase na eficácia imediata da comunicação" (p. 186). E ainda, "boa parte dos livros didáticos deixou de incluir a gramática, que cedeu lugar a conceitos oriundos da teoria da comunicação. Reduziu-se neles também o espaço da literatura, que cedeu lugar aos códigos visuais e às histórias em quadrinhos" (ibidem). Mas, de acordo com Faraco, a gramática perdeu seu lugar de prestígio apenas nos materiais didáticos e nos programas escolares, pois na prática ela continuou a ser trabalhada, obedecendo a uma tradição de ensino que vinha se perpetuando há décadas. Diante de tal cenário, o ensino da gramática que já era pobre, "ficou ainda mais pobre. Desprovido de qualquer sustentação filológica ou linguística mais consistente, o ensino da gramática se cristalizou num saber limitado, repetitivo e nada funcional" (idem, p. 187).

O fim da ditadura militar trouxe novas reformas nas leis e diretrizes educacionais. A teoria da comunicação, antes a base para o ensino de língua, agora cede lugar para as teorias sócio-interacionistas de fonte vigotskiana. A prática em sala de aula, porém, segue da mesma forma, perpetuando "as clivagens entre o currículo formal, produzido pelo poder educacional, e o currículo real, vivido nas salas de aula por professores, alunos e demais participantes da comunidade escolar" (BITTENCOURT, 2003, p. 19).

Hoje, apesar dos inúmeros esforços despendidos na tentativa de reverter o problemático quadro do ensino de língua portuguesa pautado no ensino predominantemente gramatical, as mudanças são mínimas, quase imperceptíveis. 
Alguns apontamentos sobre o texto de apresentação da Gramática Contemporânea ...

A retomada desses acontecimentos históricos, conforme realizamos anteriormente, é de grande valia para que possamos realizar o exercício analítico, proposto no início deste trabalho, da Gramática Contemporânea da Língua Portuguesa, de Nicola e Infante.

\section{A Gramática Contemporânea da Língua Portuguesa: uma breve apresentação}

O material selecionado para análise é a $12^{\mathrm{a}}$ edição da Gramática Contemporânea da Língua Portuguesa, dos autores José de Nicola e Ulisses Infante, publicada em 1994, tendo como data da primeira edição o ano de 1967.

Destinada ao alunado do Ensino Médio, a obra constitui-se de cinco partes denominadas, pela sequência: Introdução, Fonética e Fonologia, Morfologia, Sintaxe e Suplemento. Merece maior atenção a primeira parte, nomeada Introdução. Nela o leitor encontrará informações sobre a origem e a evolução da língua portuguesa, as fases históricas do português e a geografia do português no mundo atual. Também terá acesso a algumas definições, como de linguagem, língua, fala, linguística, regionalismo, dialeto e gramática normativa. Em momento posterior de nosso trabalho, retomaremos alguns desses conceitos, que importam sobremaneira para nosso exercício analítico. As demais partes são constituídas dos conteúdos gramaticais que o título abrange e o Suplemento está dividido em tópicos que tratam de problemas gerais da língua culta, de noções elementares de semântica e de figuras de linguagem. Ainda, traz uma listagem de testes de revisão.

Em relação ao modo de apresentação dos conteúdos, há uma ordem estabelecida: primeiramente, vem a exposição do conteúdo, seu detalhamento na forma de regras e exceções ou uma explicação bastante minuciosa do uso correto das formas linguísticas trabalhadas. Logo após aparece um texto, seja ele literário, jornalístico ou de outra tipologia, acompanhado de uma série de exercícios que retomam os conteúdos gramaticais trabalhados naquele capítulo. Finalmente, segue uma listagem de questões de vestibular para que o aluno possa testar os conhecimentos adquiridos. Quando da realização das análises, abordaremos, com mais riqueza de detalhes, a ordem de apresentação de alguns conteúdos, bem como o modo como são tratados. 


\section{O texto de apresentação da Gramática de Nicola e Infante: "a língua enquanto parte social da linguagem"?}

Durante o período que correspondeu ao exercício dos militares no poder, a educação ganhou uma nova finalidade: preparar o cidadão brasileiro para o mercado de trabalho, proporcionando a ele uma formação pragmática e de pouco comprometimento com questões filosóficas e reflexivas. Isso, em função da necessidade de controlar a forma de pensar das pessoas e homogeneizar sua visão de mundo. $\mathrm{O}$ fim da ditadura militar trouxe reformulações nas diretrizes e bases do ensino, porém, a realidade em sala de aula permaneceu praticamente a mesma por vários anos. No que compete ao ensino de português, a teoria da comunicação continuou, de certa forma, presente no modo de conceber a língua. É somente em fins dos anos 1980 e inicio dos anos 1990 que o pensamento sócio-interacionista, representado no Brasil pelo educador Paulo Freire, passa a fazer parte das diretrizes curriculares do ensino. Não podemos esquecer, no entanto, que as mudanças são muito lentas no campo educacional. Assim, pois, o ensino da língua portuguesa seguiu amparado por duas bases, conforme Carlos Alberto Faraco: a língua vista sob uma égide comunicativa e a prática focada no ensino da gramática tradicional.

Passamos então, para a análise de alguns pontos do texto de apresentação da Gramática Contemporânea da Língua Portuguesa (1994), de Nicola e Infante, pois pretendemos verificar se existem incongruências entre a proposta inicial dos autores e o conteúdo, de um modo geral, presente nela.

Inicialmente, os autores declaram que seu material se dirige ao aluno, prioritariamente, e não ao professor, como até então se tinha realizado, pois consideram o professor como "um orientador do aluno, um companheiro do aluno na descoberta das possibilidades lingüísticas" (1994, p. 5). Desse modo, "nossa gramática é, fundamentalmente, um diálogo com o aluno, diálogo em que se procura discutir a linguagem, sentir a linguagem, viver a linguagem" (ibidem).

O que se percebe, todavia, no desenvolvimento dos temas propostos, é a apresentação de conteúdos bastante complexos e a presença de uma metalinguagem, muitas vezes inacessível ao público discente, que dificultaria significativamente o pretenso "diálogo" direto com o aluno. Para tornar mais clara nossa colocação, apresentaremos um exemplo. 
Na segunda parte da gramática, aparece o tópico Acentuação gráfica. A ele segue a orientação de quando uma palavra deve receber acento. Tal orientação é feita da seguinte forma:

O filólogo Mário Barreto nos explica que "não são acentuados os vocábulos que seguem a regra geral da própria prosódia portuguesa". Essa "regra geral" é simples: em português, a maioria das palavras é paroxítona terminada em a(s), e(s), o(s), em(ens). Essa maioria não é acentuada graficamente (p. 61).

Na sequência, as regras de acentuação são elencadas, após segue um texto e muitos exercícios para fixar as regras.

Não há, pois, diálogo algum entre a gramática e o aluno. O que há é uma explicação extremamente complexa para o entendimento de um estudante de Ensino Médio e uma série de exercícios, que não lhe permitem criar nada novo nem refletir sobre uma dada situação linguística comum ao seu meio. Do aluno apenas se exige a memorização da regra e sua reprodução.

Todos os tópicos gramaticais são abordados dessa forma, o que nos permite constatar a ausência total de qualquer forma de interação. $\mathrm{O}$ aprendiz deve apenas reproduzir um saber sobre a língua, sem qualquer possibilidade de criar algo que lhe permita usar na prática aquilo que aprendeu na forma de regra.

Já na citação em que os autores afirmam que seu objetivo é "discutir a linguagem, sentir a linguagem, viver a linguagem", observamos que o conceito "linguagem" é tomado como sinônimo de língua, mais especificamente como sinônimo de gramática da língua, já que o que se discute, o que se lê, o que se apresenta, é o conjunto das normas que regem o português culto, padrão, e não qualquer português.

Outro ponto problemático de tal citação está no fato de os autores apresentarem, na primeira parte da gramática, uma definição de linguagem que não coincide com a que está no texto de apresentação. Na página 19, a linguagem é caracterizada como:

uma palavra sempre relacionada a fenômenos comunicativos. Onde há comunicação, há linguagem: como o homem é um ser social, sua necessidade de estabelecer comunicação é praticamente ininterrupta. Enviando ou recebendo mensagens por meio de um código, o ser humano atende a sua necessidade comunicativa, criando a atividade a que se dá o nome linguagem [grifo nosso]. 
Logo, a linguagem é definida como "um processo de comunicação de uma mensagem entre dois sujeitos falantes pelo menos, sendo um destinador ou emissor, e o outro, o destinatário ou receptor" (ibidem).

Não há como negar a influência da teoria da comunicação nestas passagens transcritas. A linguagem é reduzida à condição de ferramenta para a comunicação humana. Como entender, então, tal conceito associado a um conjunto de regras que normatizam apenas uma variedade da língua portuguesa, a língua padrão? Estamos diante de outro paradoxo.

Nicola e Infante dão continuidade à apresentação da gramática: "convencidos de que a palavra isolada é um fato artificial, elaboramos os apêndices de morfossintaxe, em que cada classe gramatical é vista de maneira dinâmica, em sua inter-relação com as demais, no todo significativo que é frase" (idem, p. 5).

O dinamismo, neste caso, é trabalhar uma regra dentro da "grande" unidade frase. Haveria, porém, outra forma de trabalhar as regras de uso da crase e as regras de pontuação, sem se chegar, pelo menos, ao nível da frase? Impossível. Nada há de novidade nisso. Os apêndices de morfossintaxe estão distribuídos da mesma forma que os demais conteúdos: exposição das regras, das exceções e listagem de exercícios de fixação.

Chegamos, então, a um trecho muito interessante do texto de apresentação. Nele, Nicola e Infante defendem que "nenhum fato gramatical é apresentado de forma, teoricamente, estéril; afinal, a língua é 'a parte social da linguagem', e seu aprendizado deve ser uma vivência constante e instigante” (idem, p. 6).

À primeira vista, percebemos uma grande incoerência nas palavras dos autores, pelo fato de eles conceberem a língua como "parte social da linguagem", sem referir, em momento algum, a presença de um sujeito que usa a língua para suas interações sociais. Se o social importa para o uso da língua, por que ele não aparece na gramática? E mais, como entender o aprendizado da língua como uma "vivência constante e instigante" se o sujeito aprendiz não vê aquilo que memoriza na forma de regras como algo de sua vivência? Vamos dar alguns exemplos.

No ponto em que aparece uma listagem de prefixos, sufixos e radicais, o aluno se depara com palavras como: soto-mor, sota-capitão, justalinear, catacrese, catapulta, arcipreste, prognóstico, silepse, barcaça, barbaça, naviarra, 
bocarra, corpanzil, gatázio, copázio, cabeçorra, beiçorra e muitas outras mais. Parece um tanto exagerado imaginar que tais vocábulos possam fazer parte da "vivência constante" dos alunos e, neste caso, é praticamente impossível não conceber o exercício de memorização dos prefixos e sufixos elencados como "estéril", já que eles são completamente desconhecidos para a grande maioria dos alunos, quando agregados a um radical na formação de palavras de raro emprego no uso cotidiano da língua.

Outros "fatos da língua" que podem ser considerados "estéreis" e que constam na gramática são o tempo verbal pretérito mais-que-perfeito e a cansativa lista de números ordinais, multiplicativos e fracionários tais como: quadringentésimo, quingentésimo, sexcentésimo, septingentésimo, sétuplo, óctuplo, nônuplo, décuplo, setenta avos, oitenta avos, noventa e um avos, etc. Há muitos outros casos que podem ser considerados "estéreis", no entanto, somente o fato de o aluno ver que a língua que ele usa e que é de sua "vivência constante" não coincide com a língua (gramática) que está no seu material didático, já é por si só um aprendizado estéril.

O próximo fragmento do texto de apresentação da Gramática Contemporânea da Língua portuguesa que merece destaque é:

Não há passagem em que não se procure valorizar a expressividade da seleção vocabular e da construção sintática, incutindo no aluno a percepção dos valores afetivos da linguagem. Daí a presença de textos inteiros para estudo, nunca de frases isoladas. Daí, também, não resistirmos à tentação de ver na gramática um instrumento de interpretação do mundo (p. 6).

Este trecho remete a uma citação de Paulo Freire, que aparece logo após para legitimar o que foi dito: "A leitura do mundo precede a leitura da palavra e a leitura desta implica a continuidade da leitura daquele".

A presença de textos inteiros e não apenas de frases isoladas é o argumento usado para defender a tese de que isso é o suficiente para que o aluno possa fazer uma leitura do mundo e não apenas de palavras. Não há, porém, ao longo de toda a gramática, nenhum exercício que leve o aluno a refletir sobre as diferentes variedades linguísticas do português, sobre os contextos de produção e de uso de tais variedades, sobre o que está sendo dito em cada texto e a forma como está sendo dito. A presença de textos diversificados na gramática é um mero pretexto para explorar o conteúdo gramatical estudado 
e para retomá-lo. Isso acaba prejudicando mais ainda o entendimento das questões da língua, pois o aluno vê a regra funcionando dentro da microestrutura frase e não consegue transpor o que aprendeu para o nível do texto.

Finalmente, chegamos ao último ponto de análise da apresentação da gramática de Nicola e Infante. Centramo-nos no que os autores denominam uma "novidade nos livros de gramática", que é "a elaboração de questões que levam a respostas pessoais, estimulando a reflexão" (p. 6) e que está presente no material didático que estão apresentando. Realmente há questões de respostas pessoais, mas, em número muito reduzido, quase inexpressivo. Quando aparece alguma questão dessa modalidade, ela é sempre a última de uma série de exercícios de fixação, fato este que lhe confere importância secundária diante do elenco das demais atividades. Por outro lado, as perguntas ditas "reflexivas" são bastante genéricas, dificultando ou até impedindo um posicionamento crítico sobre os assuntos por parte dos alunos. A título de exemplo, mencionamos o poema de Oswald de Andrade Medo da Senhora, que aparece na página quarenta. A pergunta reflexiva sobre este texto é: "Você concorda com a atitude da escrava? Vale a pena viver sem liberdade?"

Considerando o fato de o período de produção da gramática ser de pós-ditadura, como um aluno teria condições de falar de liberdade, se até em então o governo exercia controle sobre ela? Como falar de liberdade, opinar sobre o direito a ela, partindo de um poema de quatro linhas, cuja temática é a falta de liberdade na época da escravidão? Diante dessa realidade, o aluno não terá condições de responder nada além de "sim" ou "não". Faltam-lhe bases para realizar uma leitura do mundo.

Citamos outros dois exemplos que confirmam nosso argumento.

A partir da leitura do poema de quatro linhas Quem é o teu inimigo?, de Bertold Brecht, o aluno se depara com a seguinte questão "reflexiva": "Brecht nos fala de ladrões que têm fome e ladrões que não têm fome. Explique, com suas próprias palavras, essa diferença." E, ainda, um último exemplo. Após ler o texto intitulado Uma estrela, vista através de periscópio, de Eduardo Alves da Costa, e fazer uma série de exercícios gramaticais, há mais uma questão a ser respondida: "E para você, o que é uma estrela?"

Podemos concluir, então, que as poucas "questões reflexivas" presentes na gramática, não dão conta de fazer o aluno refletir verdadeiramente 
sobre as temáticas dos textos apresentados. O exercício "reflexivo" torna-se, por isso, também estéril.

\section{Considerações finais}

As análises realizadas anteriormente nos permitem, de certa forma, responder à pergunta inicial que lançamos e também dão a base para construirmos os conceitos de língua, gramática, ensino de língua, aluno e professor que funcionam na Gramática Contemporânea da Língua Portuguesa (1994).

O ensino de língua portuguesa para alunos do Ensino Médio, considerando os conteúdos e a forma pela qual eles são apresentados e discutidos na gramática de Nicola e Infante, é calcado, primordialmente, no ensino das regras gramaticais que regem o uso do português culto ou padrão, de expressão escrita. Nesse sentido, a língua é vista somente como sinônimo dessa variedade padrão, que é apenas uma em meio a tantas outras faladas e escritas em todo o imenso território brasileiro. Mesmo que os autores definam, na página 20, a língua como "o mais importante" código comunicativo, devido a seu uso "universal e generalizado nos diferentes grupos sociais", e afirmem seu "caráter social", o que se observa no material didático é uma concepção de língua associada à norma culta, que somente pode ser estudada e aprendida através da apresentação e da memorização de suas regras.

A teoria da comunicação está presente na gramática, porém, em um momento restrito: na primeira parte, onde os autores apresentam um panorama histórico da origem e evolução da língua portuguesa e onde mencionam um conceito de língua, linguagem e gramática normativa. A visão de língua enquanto código comunicativo é abandonada nas demais partes do texto, já que se privilegia a exposição do sistema de regras que funcionam no português padrão. A concepção de gramática, conforme vimos, é a mesma de língua, e o ensino da língua é, basicamente, o ensino das normas gramaticais do português culto.

O aluno, por sua vez, é aquele sujeito dependente das orientações e dos esclarecimentos do professor, apesar de os autores do material afirmarem haver entre eles e o aluno "um diálogo", graças à forma como "os fatos da linguagem" são apresentados e discutidos. Constatamos que o almejado diálogo depende da interferência do professor - o guia - em virtude da complexidade dos temas abordados e do uso de uma metalinguagem, certamente 
desconhecida para o aluno; e muitas vezes, nem com ajuda do professor, que se esforça para parafrasear o que foi dito na gramática, o alunado entende e aprende verdadeiramente suas normas.

A partir das discussões realizadas neste trabalho, sugerimos uma possivel resposta para a questão do fracasso no ensino de língua portuguesa no Brasil: a existência de uma enorme lacuna entre as teorias que dão base ao ensino de língua e a prática real em sala de aula, associada a uma visão de língua padrão, homogênea, que corresponde a uma variedade apenas do grande conjunto. Assim, concluímos que a Gramática Contemporânea da Língua Portuguesa poucas inovações apresenta, no que tange ao ensino de língua propriamente, já que o que se observa nela é a continuidade da tradição gramatical de ensino de língua.

\section{Referências}

BITTENCOURT, C. M. F. Disciplinas escolares: história e pesquisa. In: OLIVEIRA, M. A. T. de; RANZI, S. M. F. (Orgs.). História das disciplinas escolares no Brasil: contribuições para o debate. Bragança Paulista: EDUSF, 2003, p. 9-38.

FARACO, C. A. O ensino do português do Brasil: alguns paradoxos e desafios. In: FARACO, C. A. Norma culta brasileira: desatando alguns nós. São Paulo: Parábola, 2008.

NICOLA, J. de; INFANTE, U. Gramática contemporânea da língua portuguesa. 12. ed. São Paulo: Scipione, 1994.

SOARES, M. Português na escola: história de uma disciplina curricular. São Paulo: Loyola, 2002, p.155-177.

. O livro didático como fonte para a história da leitura e da formação do professor-leitor. In: MARINHO, M. (Org.). Ler e navegar: espaços e percursos da leitura. Campinas, SP: Mercado das Letras: Associação de Leitura do Brasil - ALB, 2001, p. 31-76.

Recebido para publicação em 8 nov. 2010. Aceito para publicação em 20 dez. 2010. 